\title{
Discovery of Eco-compatible Synthetic Paths by a Multi-catalysis Approach
}

\author{
Jean Rodriguez and Adrien Quintard*
}

\begin{abstract}
This article summarizes our recent developments in the discovery of multi-catalytic reactions. By efficiently taking the best from different worlds, the combination of several catalytic principles allows the invention of eco-compatible transformations rapidly assembling simple building blocks into elaborated enantioenriched molecules. This type of approach was successfully illustrated in the synthesis of cyclohexenones, keto-diols or in the direct functionalization of allylic alcohols by an enantioselective borrowing hydrogen. In addition, mechanistic understanding of the role of the different constituents enabled the fine-tuning of the catalytic systems considerably improving the efficiency notably in terms of enantiocontrol.
\end{abstract}

Keywords: Copper · Enantioselective synthesis · Eco-compatibility · Iron · Multi-catalysis · Organocatalysis

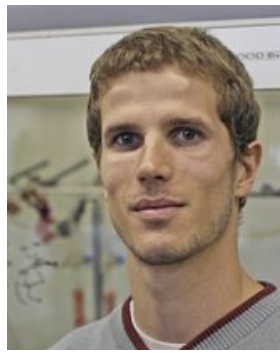

Adrien Quintard studied chemistry at the University of Toulouse (IUT) and then at $\mathrm{CPE}$ University of Lyon. He completed his $\mathrm{PhD}$ in 2011 under the supervision of Prof. A. Alexakis at the University of Geneva. He subsequently moved to the University of Stanford for a first post-doctoral stay working with Prof. B. M. Trost. After moving to Aix-Marseille University in 2012 for a second post-doctoral position, he obtained in 2013 an ANR research grant allowing him to start his own research program on the development of multi-catalyzed transformations before becoming in 2014 CNRS researcher. Recently, he was recognized by the young researcher 'Emergence' award from the organic division of the French Chemical Society and he was a recipient of a Thieme Chemistry Journals Award.
${ }^{\star}$ Correspondence: Dr. A. Quintard

Aix-Marseille Univ., CNRS

Centrale Marseille, iSm2

Marseille, France

E-mail: adrien.quintard@univ-amu.fr

\section{Introduction}

Organic chemistry has continuously evolved during the last decade allowing the generation of molecular frameworks of increasing complexity. Today, it appears that even the more complex natural products such as maitotoxin, a molecule possessing 98 stereogenic centers, should be accessible through organic chemists skills. ${ }^{[1]}$ This huge potential has been demonstrated at the industrial level with the preparation of eribulin. This last generation anti-cancer treatment, a highly complex molecule possessing 19 stereogenic centers, is currently prepared on the industrial scale through the use of organic chemistry transformations. ${ }^{[2]}$ However, when closely looking at the parameters associated with synthetic efficiency such as redox, atom, step or protecting group economies, ${ }^{[3]}$ the 62 -step sequence required for the preparation of this drug is clearly not eco-compatible. As a result, chemists must continue to develop improved synthetic tools to be able to prepare all possible complex molecules rapidly, while minimizing waste generation.

To find solutions to this problem, for years scientists have relied on the use of a single catalytic activation mode. However, even though more efficient and selective catalysts are continuously being discovered, using only one catalyst might limit reaction potential. In answer to these apparent limitations, researchers have started looking at the selective combination between multiple catalysts. Taking the best from different worlds, notably from the fields of metal- and organo-catalysis, new mechanistic paths with improved efficiency were discovered facilitating the preparation of complex molecules (Scheme 1). ${ }^{[4]}$

In the present article, we summarize our recent efforts at developing innovative multi-catalytic combinations. This work has allowed the discovery of various strategic paths enabling considerable synthetic economies.

\section{Bio-resourced Keto-diacid in Multi-catalysis Cascades}

In order to discover attractive synthetic routes, one must be able to assemble widely available materials into molecular frameworks of value. In this context, we recently took advantage of the peculiar reactivity of 1,3-acetonedicarboxylic acid (1), a bio-resourced molecule prepared in

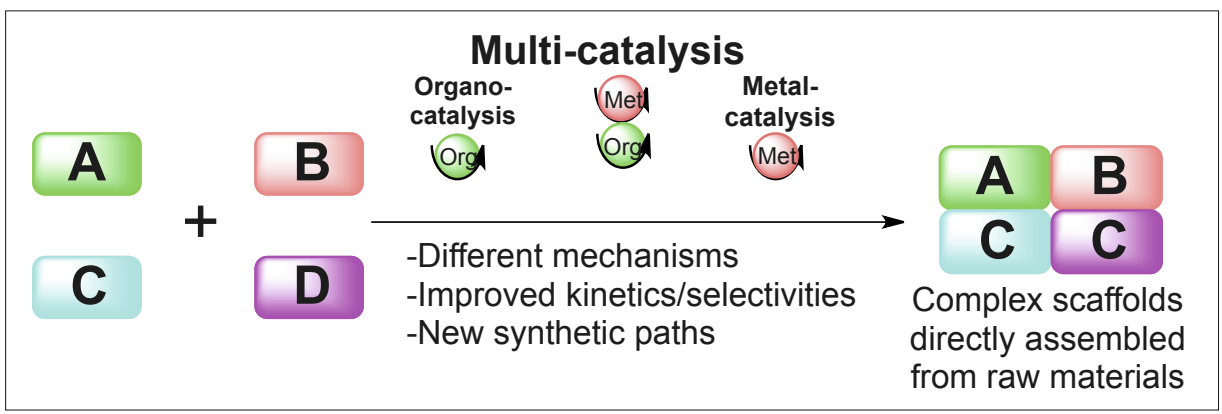

Scheme 1. Multi-catalysis assembly line. 
kilogram scale from citric acid. This molecule is able to react in a bi-directional manner much faster than acetone while liberating two molecules of $\mathrm{CO}_{2}$ as single waste. ${ }^{[5]} \mathrm{We}$ initially attempted to condense $\mathbf{1}$ with cinnamaldehyde $\mathbf{2} \mathbf{a}$ using an iminium activation promoted by secondary amine cat1 (Scheme 2). After 1,4-addition of 1 to the $\alpha, \beta$-unsaturated aldehyde, subsequent crotonization should provide chiral cyclohexenone $\mathbf{3 a}$.

Disappointingly, using a single catalytic activation mode, the cyclohexenone 3a was obtained in moderate $12 \%$ yield and only $90 \%$ ee. However, turning to multi-catalysis considerably modified the reaction profile. Adding $6 \mathrm{~mol} \%$ of $\mathrm{Cu}(\mathrm{i}$ $\mathrm{BuCOO})_{2}$, the final cascade product could be isolated in $50 \%$ yield. ${ }^{[6]}$ Moreover, the enantiocontrol was also improved to $>98 \%$ ee highlighting the beneficial modification in the 1,4-addition transition state (enantio-determining step). This result indicates that a synergistic mechanistic pathway is occurring where the electrophile is activated through iminium ion formation and the nucleophile is activated by the copper catalyst. Coordination of keto-diacid $\mathbf{1}$ with Lewis acids such as $\mathrm{Fe}$ (acac) ${ }_{3}$ could further be observed by UV titration, confirming the potential activation of the nucleophile by the copper salt. [7] With this new synergistic copper-organo-catalytic tool in hand, different chiral enones of interest could be prepared directly in excellent enantiocontrol (>94\% ee). ${ }^{[8]}$

The discovery that Lewis acids such as simple copper salts could activate keto-diacid 1 prompted us to investigate the parent challenging bi-directional aldoliza- tion (Scheme 3). Condensing in a cascade a ketone equivalent on two molecules of aldehydes $\mathbf{4}$ directly provides keto-diols $\mathbf{5}$, direct precursors of 1,3,5-polyols, a motif of crucial importance present in numerous bio-active molecules (nystatin, peloruside, halichondrin, bryostatin, amphotericin B). However, despite the interest of this reaction, performing a catalytic bi-directional aldolization notably using the most interesting aliphatic aldehydes remained an unmet challenge when we started our investigations. ${ }^{[9]}$

In this context, we discovered that under mild conditions, 15 mol\% of $\mathrm{Fe}(\mathrm{acac})_{3}$ or $\mathrm{Cu}(\mathrm{acac})$, could selectively activate both keto-diacid $\mathbf{1}$ and aldehydes $\mathbf{4}$ to favor the formation of the desired keto-diols $\mathbf{5}$ (Scheme 3). ${ }^{[7]}$ However, even though challenging aliphatic aldehydes could be used in the transformation, the diastereoselectvities remained modest $(1.2: 1 \mathrm{dr}$ for $\mathbf{5 a})$. In addition, the development of an efficient enantioselective version of this transformation was hampered by the competition between coordination of the keto-diacid and a chiral ligand to the metal center.

However, when a chiral center was placed in $\alpha$-position of the starting aldehyde, a diastereoselective bi-directional aldolization was observed (Scheme 3). For example, the major diastereomer of $\mathbf{5 b}$ could be formed in around $80 \%$ selectivity highlighting the strong facial selectivity control during the addition of $\mathbf{1}$ to the chiral aldehyde.

This result prompted us to further investigate other bi-directional reactions by attempting to tackle the construction of complex fluorinated polyols. Indeed, inserting fluorine atoms represents a method

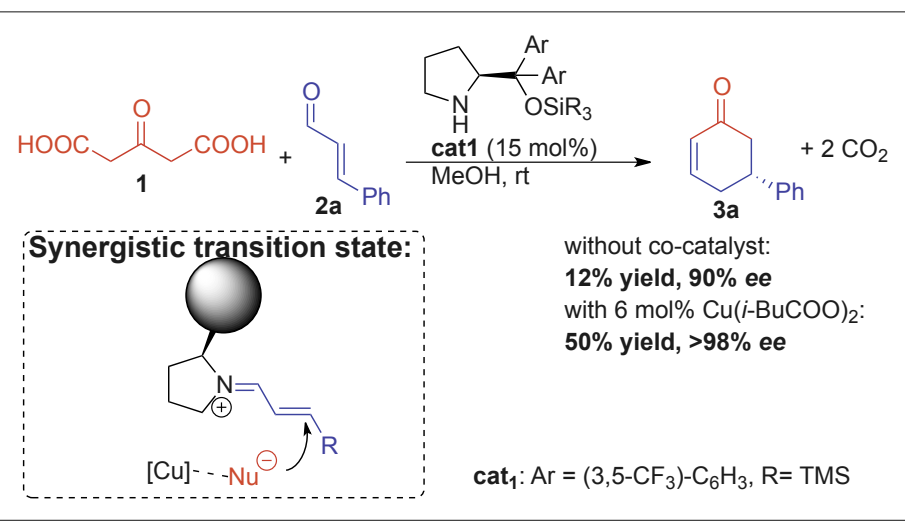

Representative examples:

of choice to modulate properties of organic molecules such as lipophilicity, conformation or acidity but remains a considerable challenge as soon as complex molecules are concerned. ${ }^{[10]}$ We recently questioned whether introducing fluorine in extended polyols would improve their bioactivity profile. ${ }^{[11]}$ However, the efficient construction of these fluorinated polyols required the development of innovative stereoselective cascades. In this context, the preparation of fluorinated keto-diols through a bi-directional aldolization would be of high interest to rapidly incorporate polyfluorinated polyols into biologically active structures.

In order to successfully develop the projected transformation, sensitive enantioenriched fluorinated aldehydes 7 easily prone to racemization had to be generated and in situ selectively derivatized (Scheme 4). For this purpose, we hypothesized that a multi-catalytic combination between an amine-catalyzed aldehyde fluorination (enamine activation), ${ }^{[12]}$ and a selective aldolization would directly generate acyclic keto-diols 6 possessing four acyclic stereogenic centers and incorporating two fluorine atoms.

Gratifyingly, the mild conditions required for the copper-catalyzed bi-directional aldolization allowed the generation of the expected keto-diols in $>98 \%$ ee. Moreover, equal efficiency was obtained when performing the reaction in one-pot consecutive manner or directly mixing all reactants at the onset (cascade). This highlights the perfect selectivity of the different catalysts notably to avoid side reactions such as the direct condensation of the keto-diacid with NFSI or with the starting aldehyde 4.

Finally, when closely monitoring the reaction by mass spectrometry, we could observe the formation of the aldol adduct prior to $\mathrm{CO}_{2}$ loss. ${ }^{[13]}$ This observation together with the formation of the major antiisomer suggest a chair-like six-membered transition state for the aldolization with additional copper coordination to the aldehyde. Dipole-dipole repulsion between the fluorine and the aldehyde would explain the observed anti-diastereoselectivity (Scheme 4). ${ }^{[14]}$

\section{Enantioselective Borrowing Hydrogen Cascades}

Scheme 3. Initial bidirectional aldolization.
In borrowing hydrogen transformations, a metal catalyst activates in a transient manner an organic molecule through reversible hydrogen transfer. The most famous representative example of this class of reactions is the direct alcohol amination. ${ }^{[15]} \mathrm{A}$ wide range of different metal complexes are able to promote these 
reactions by catalyzing the transformation of alcohols to aldehydes and the final imine reduction. However, despite the considerable economies these borrowing hydrogens allow, only limited examples of enantioselective variants are known. ${ }^{[16]}$

In 2013, we reported an original approach to promote such enantioselective borrowing hydrogen based on multi-catalysis (Scheme 5). ${ }^{[17]}$ By combining an ironcyclopentadienone complex catalyzed borrowing hydrogen ${ }^{[18]}$ with an iminium activation, the direct functionalization of widely available allylic alcohols directly afforded chiral alcohols. Through the nucleophilic addition of commercial 1,3-dicarbonyl compounds 8 (keto-esters or diketones), the final substituted alcohols 10 were formed in up to $92 \%$ ee. In the case of diketones $\left(\mathrm{R}^{1}, \mathrm{R}^{2}=\right.$ alkyl or aryl) additional spontaneous cascade occurred directly forming synthetically useful protected alcohols 11.[11b]

In order to shed light on the role of the different reaction constituents, a more complete mechanistic investigation was undertaken.[19] Careful kinetic analysis indicated a relatively original reaction profile. Notably, the iron complex influenced the global kinetic of the transformation if used below $10-15 \mathrm{~mol} \%$. When the amount of iron complex [Fe] was sufficient, it no longer influenced the reaction rate. On the contrary, nucleophiles $\mathbf{8}$, allylic alcohols 9 and cat1 all positively influenced the kinetics. Taken altogether, our study suggested that the kinetic bottleneck of the multi-catalysis consisted in the 1,4-addition of the 1,3-dicarbonyl to the iminium ion, the allylic alcohol stabilizing the enol form of the nucleophile. This particular point was confirmed by focusing on the Michael addition to preformed $\alpha, \beta$-unsaturated aldehydes 2 where allylic alcohols influenced both kinetic and enantiocontrol. The reason for the influence of the iron complex on the kinetic at low relative concentration is due to the interconnection between both hydrogen transfer and iminium catalytic cycles. Indeed, the amount of iron complex $[\mathrm{Fe}]$ directly influences the maximum amount of intermediate $\alpha, \beta$-unsaturated aldehyde. ${ }^{[20]}$ If a low relative concentration in $[\mathrm{Fe}]$ is used, the concentration in the intermediate aldehyde is too small to favor iminium ion formation. In contrast, as soon as this concentration is sufficient, the formation of the reactive iminium ion is rapid and the Michael addition becomes the unique rate-determining factor.

This crucial observation allowed us to further optimize the multi-catalytic system. Since the allylic alcohols 9 are involved in the stabilization of the transition state of the nucleophilic addition, it should be likely to positively replace it
Scheme 4. Multicatalytic fluorinated keto-diols synthesis.
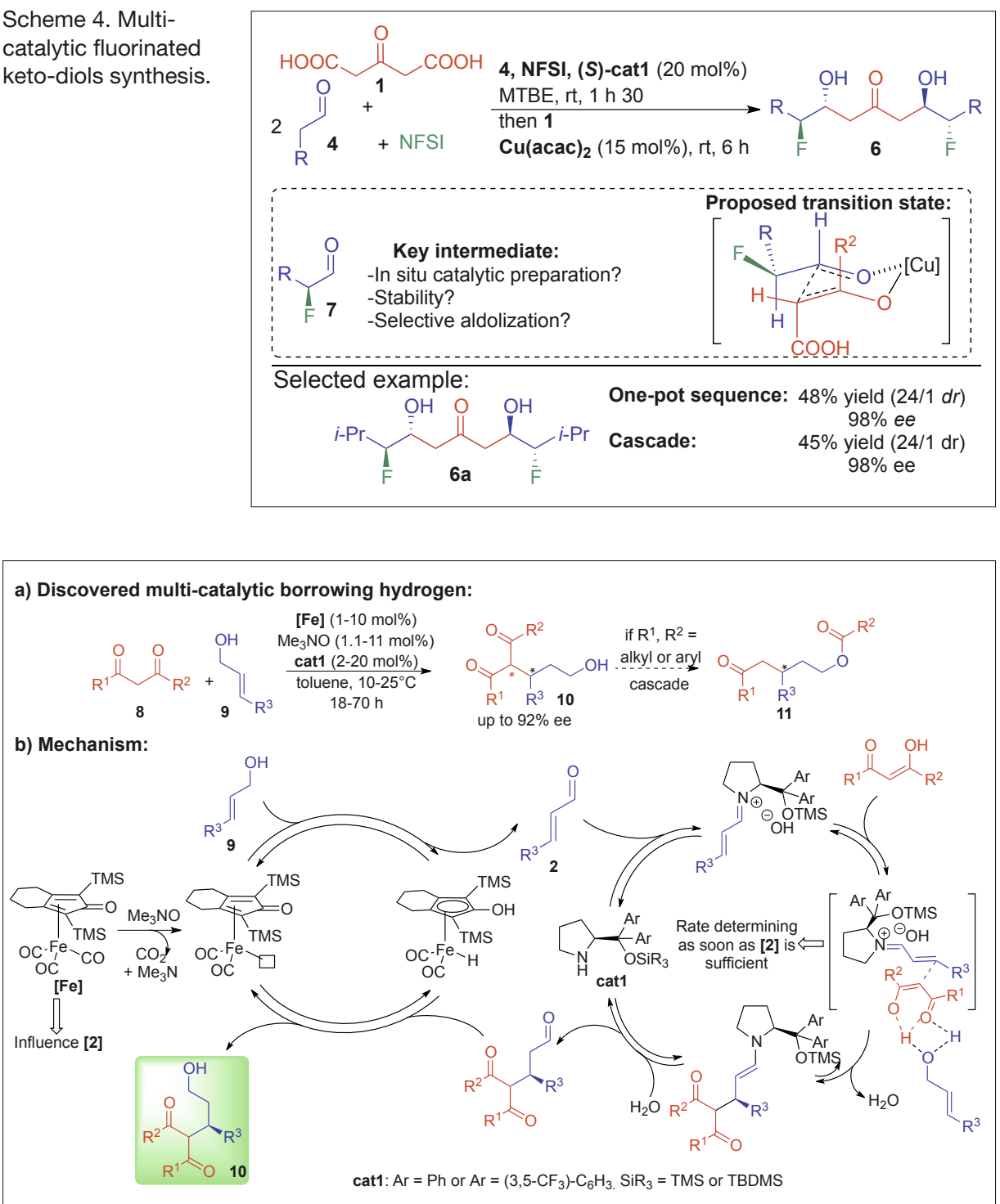

Scheme 5. Multi-catalytic borrowing hydrogen.

by another activating agent, possibly catalytic. Taking advantage of our previously mentioned reports on the dual activation of nucleophiles by copper salts (Scheme 2 ), we added a third catalyst to the enantioselective borrowing hydrogen. Thanks to the synergistic role of this additional 5 $\mathrm{mol} \% \mathrm{Cu}(\mathrm{acac})_{2}$, an impressive increase in reaction efficiency was observed and both yields and enantioselectivities were raised (Scheme 6). Starting from ketoesters, diketones, keto-sulfones or nitroesters, the positive effect of the third copper catalyst allowed the isolation of the terminal alcohols in ee's ranging from 68 to $96 \%$.

\section{Conclusion}

The selective combination of multiple catalytic activation modes has recently changed the way chemists conceive organic transformations. This approach allows fundamental synthetic challenges to be tackled by providing innovative solutions to activate organic molecules. Following these principles, our group has designed successful combinations between copper- and organo-catalysis to condense keto-diacids to aldehydes. The synthetic relevance of these methodologies was demonstrated in the rapid preparation of key cyclohexenones or keto-diols.

Finally, the development of the first efficient enantioselective borrowing hydrogen was enabled through the combination between an organocatalyst and an iron hydrogen transfer complex. Mechanistic rationalization of the reaction led us to further optimize the system by incorporating a third catalyst to the transformation. Thanks to this unique triple-catalysis, the selective functionalization of allylic alcohols directly afforded substituted aliphatic alcohols in up to $96 \%$ ee.

These findings open strong perspectives notably to discover new eco-compatible transformations and to apply these methodologies in the rapid and waste-free synthesis of natural products or bioactive molecules.[21] 
Scheme 6. Triplecatalytic borrowing hydrogen.

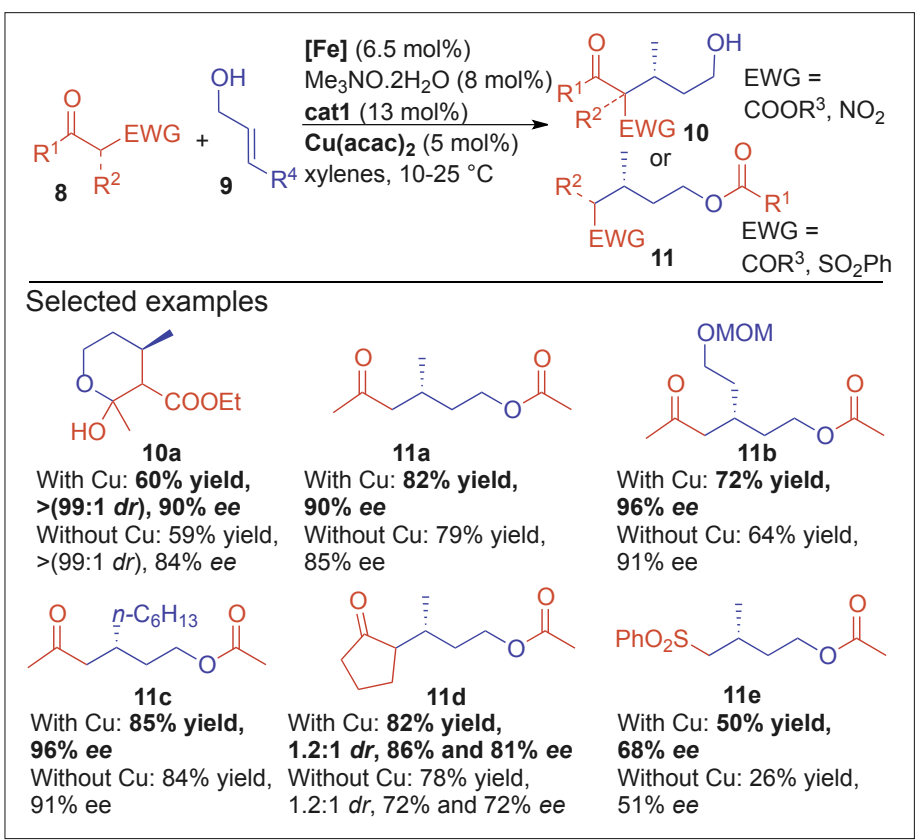

\section{Acknowledgements}

The Agence Nationale pour la Recherche (ANR-13-PDOC-0007-01), the Centre National de la Recherche Scientifique (CNRS) and the Aix-Marseille Université are gratefully acknowledged for financial support. All the people who have been involved in the multi-catalytic projects, Mylène Roudier, Céline Spérandio, Angela Ricucci, Thierry Constantieux, are greatly acknowledged for their contribution to this work.

Received: February 23, 2018

[1] K. C. Nicolaou, P. Heretsch, T. Nakamura, A Rudo, M. Murata, K. Konok, J. Am. Chem. Soc. 2014, 136, 16444.

[2] H. Ledford, Nature 2010, 468, 608.

[3] a) J. B. Hendrickson, J. Am. Chem. Soc. 1975 , 97, 5784; b) B. M. Trost, Science 1991, 254, 1471; c) R. A. Sheldon, Chem. Soc. Rev. 2012, 41, 1437; d) P. A. Wender, B. L. Miller, Nature 2009, 460, 197; e) T. Gaich, P. S. Baran, J. Org. Chem. 2010, 75, 4657 .

[4] a) A. E. Allen, D. W. C. MacMillan, Chem. Sci. 2012, 3, 633; b) Z. Du, Z. Shao, Chem. Soc. Rev. 2013, 42, 1337; c) S. M. Inamdar, V. S. Shinde, N. T. Patil, Org. Biomol. Chem. 2015, 13, 8116.

[5] Historically, the corresponding $\mathrm{Ca}$ salt was used by Robinson in the famous 1917 tropinone synthesis: a) R. Robinson, J. Chem. Soc. Trans. $\mathbf{1 9 1 7}, 111,762$. For other use of $\mathbf{1}$ in a catalytic Griffin, P. A. O'Donnell, R. C. J. Dobson, M. A. Perugini, J. A. Gerrard, C. A. Hutton, Bioorg. Med. Chem. 2008, 16, 9975; c) C. Li and B. Breit, J. Am. Chem. Soc. 2014, 136, 862.

[6] For selected other examples of synergistic copper-iminium catalysis: a) S. Afewerki, P. Breistein, K. Pirttila, L. Deiana, P. Dziedzic, I. Ibrahem, A. Cordova, Chem. Eur. J. 2011, 17, 8784; b) I. Ibrahem, S. Santoro, F. Himo, A. Cordova, Adv. Synth. Catal. 2011, 353, 245; c) Y. Wei, N. Yoshikai, J. Am. Chem. Soc. 2013, 135, 3756; e) M. Meazza, V. Ceban, M. B. Pitak, S. J. Coles, R. Rios, Chem. Eur. J. 2014, 20, 16853.

[7] A. Quintard, J. Rodriguez, Chem. Eur. J. 2015 , 21,14717 .

[8] a) A. Quintard, J. Rodriguez, Chem. Commun. 2015, 51, 9523. For an alternative approach to this type of chiral cyclohexenones see: b) A. Carlone, M. Marigo, C. North, A. Landa, K. A. Jørgensen, Chem. Commun. 2006, 4928.

[9] For selected examples of other bi-directional aldolizations: a) K. Mikami, S. Matsukawa, M. Nagashima, H. Funabashi, H. Morishima, Tetrahedron Lett. 1997, 38, 579; b) Y. Shimoda, T. Kubo, M. Sugiura, S. Kotani, M. Nakajima, Angew. Chem. Int. Ed. 2013, 52, 3461; c) G. Valero, J. M. Ribo, A. Moyano, Chem. Eur. J. 2014, 20, 17395; d) S. Kotani, K. Kai, Y. Shimoda, H. Hu, S. Gao, M. Sugiura, M. Ogasawara, M. Nakajima, Chem. As. J. 2016, 11, 376.

[10] a) D. Cahard, X. Xu, S. Couve-Bonnaire, X. Pannecoucke, Chem. Soc. Rev. 2010, 39, 558; b) transformation: b) B. E. Boughton, M. D. W.
T. Furuya, A. S. Kamlet, T. Ritter, Nature 2011 473,470 ; c) X. Yang, T. Wu, R. J. Phipps, F. D. Toste, Chem. Rev. 2015, 115, 826.

[11] For other approaches to fluorohydrins based on aldolization: a) J. T. Welch, K. Seper, S. Eswarakrishnan, J. Samartino, J. Org. Chem. 1984, 49, 4720; b) J. Saadi, M. Akakura, H. Yamamoto, J. Am. Chem. Soc. 2011, 133 14248; c) J. Saadi, H. Yamamoto, Chem. Eur. J. 2013, 19, 3842; d) J. Saadi, H. Wennemers, Nature Chem. 2016, 8, 276.

[12] M. Marigo, D. Fielenbach, A. Braunton, A Kjaersgaard, K. A. Jørgensen, Angew. Chem. Int. Ed. 2005, 44, 3703.

[13] This experiment was performed using 3-oxo3-phenylpropanoic acid.

[14] S. Díaz-Oltra, M. Carda, J. Murga, E. Falomir J. A. Marco, Chem. Eur. J. 2008, 14, 9240

[15] For reviews on the topic, see: a) G. E Dobereiner, R. H. Crabtree, Chem. Rev. 2010 , 110, 681; b) A. J. A. Watson, J. M. J. Williams, Science 2010, 329, 635; c) C. Gunanathan, D. Milstein, Science 2013, 341, 1229712.

[16] For a recent review see: a) A. Quintard, J. Rodriguez, Chem. Commun. 2016, 52, 10456. For selected examples: b) D. J. Shermer, P. A. Slatford, D. D. Edney, J. M. J. Williams, Tetrahedron: Asymm. 2007, 18, 2845; c) Y. Zhang, C-S. Lim, D. S. B. Sim, H-J. Pan, Y. Zhao, Angew. Chem., Int. Ed. 2014, 53, 1399; d) Z-Q. Rong, Y. Zhang, R. H. B. Chua, H-J. Pan, Y. Zhao, J. Am. Chem. Soc. 2015, 137, 4944.

[17] a) A. Quintard, T. Constantieux, J. Rodriguez, Angew. Chem. Int. Ed. 2013, 52, 12883; b) M. Roudier, T. Constantieux, A. Quintard, J. Rodriguez, Org. Lett. 2014, 16, 2802; c) M. Roudier, T. Constantieux, J. Rodriguez, A. Quintard, Chimia 2016, 70, 97.

[18] For reviews: a) A. Quintard, J. Rodriguez, Angew. Chem. Int. Ed. 2014, 53, 4044; b) A. Quintard, J. Rodriguez, ChemSusChem. 2016, 9,28 . For a selected example of the use of this complex: c) C. P. Casey, H. Guan, J. Am. Chem. Soc. 2007, 129, 5816.

[19] M. Roudier, T. Constantieux, A. Quintard, J. Rodriguez, ACS Catal. 2016, 6, 5236.

[20] M. Wiesner, G. Upert, G. Angelici, H. Wennemers, J. Am. Chem. Soc. 2010, 132, 6.

[21] For other recent contributions from our group in other multi-catalytic transformations see: a) A. Quintard, J. Rodriguez, Adv. Synth. Catal. 2016, 358, 3362; b) M. Roudier, J. Rodriguez, A. Quintard, Synthesis 2018, 50, 785; c) A. Ricucci, J. Rodriguez, A. Quintard, Eur. J. Org Chem. 2018, DOI: $10.1002 /$ ejoc.201701459; d) A. Quintard, C. Sperandio, J. Rodriquez, Org. Lett. 2018, doi: 10.1021/acs.orglett.8b02213. 